\title{
A MISSÃO CIVILIZADORA COMO FACTOR DE CONSTRUÇÃO DA ALTERIDADE COLONIAL EM MOÇAMBIQUE
}

\author{
THE CIVILIZING MISSION AS A FACTOR IN BUILDING COLONIAL OTHERNESS IN MOZAMBIQUE \\ Denisse Omar* \\ denissekatiaomar@gmail.com
}

RESUMO: O presente artigo procura analisar como o discurso da missão civilizadora contribuiu para a construção da alteridade colonial em Moçambique. O período colonial, que durou cerca de 500 anos em Moçambique, consequentemente, deixou marcas profundas no seio da população, sendo a mais relevante a missão civilizadora que foi o garante do sucesso da colonização, pois a partir desta missão os portugueses, à semelhança de outros europeus, ganharam o direito de civilizar os povos considerados atrasados, não respeitando assim a história desses povos. Portanto, a partir desta missão, surge a alteridade e a diferença entre "civilizados" (colonizador) e "selvagens/indígenas" (colonizado). É neste contexto que na primeira parte deste artigo faz-se alusão a questão da missão civilizadora implementada pela administração colonial como factor chave para construir a alteridade e a diferença colonial. Neste sentido, para realização deste artigo levou-se em consideração uma análise bibliográfica e documental buscando-se analisar o tópico a partir dos materiais e documentos existentes em Arquivos, centrando-se principalmente na documentação que deu mais ímpeto e clareza à pesquisa.

PalaVRAS-ChaVe: Colonialismo, Alteridade, Missão civilizadora, Assimilado.

ABSTRACT: This article seeks to analyze how the discourse of the civilizing mission contributed to the construction of colonial otherness in Mozambique. The colonial period that lasted about 500 years in Mozambique, consequently, left profound marks within the population, the most relevant being the civilizing mission that was the guarantee of the success of colonization, since from this mission the Portuguese, like other Europeans, gained the right to civilize the peoples considered backward, thus not respecting the history of those peoples. Therefore, from this mission arises the otherness and the difference between "civilized" (colonizer) and "wild / indigenous" (colonized). It is in this context that, in the first part of this article, the issue of the civilizing mission implemented by the colonial administration is mentioned as a key factor in building alterity and colonial difference. In this sense, for the realization of this article, a bibliographical and documentary analysis was taken into consideration, seeking to analyze the topic from the materials and documents existing in Archives, focusing mainly on the documentation that gave the research more impetus and clarity.

KEYWORDS: Colonialism, Alterity, Civilizing mission, Assimilated.

\section{Introdução}

Neste artigo procura-se analisar como a missão civilizadora implementada pelo governo colonial português constituiu um factor para a construção da alteridade em Moçambique durante o período colonial.

\footnotetext{
* Professora na Universidade Rovuma. Fez o seu Mestrado da Universidade Pedagógica de Maputo pelo curso de Ciências de Educação/Ensino de História e atualmente frequenta o curso de Doutoramento em História Contemporânea.
} 
$\mathrm{Na}$ linguagem comum a alteridade pressupõe que o homem na sua vertente social tem uma relação de interacção e dependência com o outro e culturalmente não tem como objectivo a extinção da outra cultura. Isto porque, de forma geral, a alteridade implica que um indivíduo seja capaz de se colocar no lugar do outro, valorizando as diferenças existentes entre eles. No entanto, o discurso da alteridade e diferença usado pela administração colonial portuguesa faz parte de uma relação existente entre a construção de nação e identidade nacional publicados por um instrumento governamental. Deste modo, constatou-se que o uso frequente do conceito de alteridade estava ligado ao sentido nacionalista, focalizando a exaltação da missão civilizacional como um dos principais fundamentos da produção de identidade nacional.

Na verdade, a ideia central da alteridade colonial era incluir os "outros", ou seja, os povos locais nos discursos coloniais como seres que deviam ser nacionalizados e incorporados na cultura do colonizador, criando assim uma nação que devia ser coerente com os objectivos do sistema colonial, visando, no entanto, a propagação das suas relações de exploração e de dominação.

Na primeira parte deste artigo, procuro analisar a missão civilizadora e a ideia da formação do assimilado. É importante relatar essa história que ainda é pouco explorada e entender como, desde cedo, a questão sobre o "eu" (colonizador) e "outro" (colonizado) fez parte do processo discriminatório da história de Moçambique. É neste contexto que, na segunda parte, faz-se alusão a questão da missão civilizadora como factor chave para construção da alteridade implementada pela administração colonial. Neste sentido, para realização deste artigo, levou-se em consideração uma análise bibliográfica e documental buscando-se analisar o tópico a partir dos materiais e documentos existentes em Arquivos, centrando-se principalmente na documentação que deu mais ímpeto e clareza à pesquisa.

\section{A Missão Civilizadora e a formação da classe dos assimilados}

A missão civilizadora em África, de forma particular em Moçambique, significou a superioridade moral e cultural dos povos europeus, o que lhes valeu o direito, e sobretudo o dever, de exercer seu poder de dominação e exploração sobre os considerados povos atrasados, neste caso o povo de moçambicano. Segundo Meneses (2010), civilizar tornou-se, a partir de meados do século XIX, a pedra angular da doutrina colonial europeia em relação aos territórios colonizados. Neste contexto, Portugal adoptou, como parte integrante da sua 
estratégia governativa, a missão política de civilizar os povos autóctones. Segundo a mesma autora, o conceito de "civilização" combinava vários pressupostos que justificavam a superioridade da cultura portuguesa e a possibilidade de as culturas 'outras' poderem melhorar as suas qualidades como resultado desse encontro demostrando que os súbditos coloniais de Portugal eram inferiores e incapazes de se autogovernarem. Partindo igualmente da ideia de que Portugal possuía uma certa vantagem, pela sua superioridade moral e material, para realizar esta tarefa. Desta forma, à semelhança de outros países europeus, Portugal defendia o direito histórico de fomentar o progresso dos povos considerados atrasados em função do seu desenvolvimento económico, cultural e político. Nessa ordem de ideias, segundo Meneses (2006), criou-se categorias legais subalternas, como foi o caso dos "indígenas" nos territórios africanos de Angola, da Guiné e de Moçambique.

Segundo Cabaço (2010), a missão civilizadora implementada em Moçambique caminhou sobre dois carris: o trabalho, em primeiro lugar, e a acção educativa, como esforço complementar. Esta acção, portanto, passava pelo exercício educacional para a prática produtiva da transmissão de valores éticos, religiosos, cívicos e comportamentais para a sua aprendizagem através do esforço laboral ao serviço do colonialismo. Neste contexto, o trabalho e a educação constituíam um instrumento de incorporação, ou seja, através desses instrumentos o governo colonial conseguiu delimitar os espaços sociais entre os brancos e negros, pois havia trabalhos que só os negros indígenas deviam exercer ao mesmo tempo que existiam escolas chamadas de rudimentares só para negros. Assim, através desses elementos, o negro foi segregado e marginalizado na sociedade colonial.

Para Medina (2016), a metanarrativa do conceito de "missão civilizacional" é um elemento discursivo que dá forma à representação da alteridade colonial. A missão civilizacional é, portanto, uma produção de sentido próprio de qualquer estado imperial, como é o caso de Portugal, onde se confrontam três formas de perceber a alteridade colonial que normalmente está amplamente ligada ao tipo de colônia que se pretende explorar, como se observa a seguir:

a) Como sujeição: um sistema no qual a política colonial "tem unicamente por fim o interesse da metrópole, que só procura possuir colónias para argumentar o próprio poder e a riqueza. A condição que deste fim resulta para a colónia é a de inteira subordinação à metrópole"; 
b) Como assimilação: um sistema que "propõe-se desenvolver nas colónias uma civilização igual a da mãe-pátria, procurando insinuar-lhes as mesmas ideias, sentimentos e aspirações; ou seja, deviam estar em uma perfeita igualdade com a metrópole, pois às colónias eram consideradas como um simples prolongamento do solo da mãe-pátria";

c) Como autonomia: um sistema que "propõe desenvolver nas colónias uma civilização própria em harmonia com as condições de existência e desenvolvimento do meio colonial; quanto à condição, as colónias ficam tendo uma certa independência. Elas governam-se a si próprias, regendo-se por leis feitas in loco pelos seus habitantes ou representantes idóneos, não tendo com a mãe-pátria senão relações de carácter restrito, tendentes apenas a assegurar a soberania política da metrópole e a protecção da colónia contra poderes estrangeiros".

De salientar que, a partir destas propostas colocadas, a que mais teve apoio foi a ideia da formação de uma classe de assimilados com objectivo de humanizar os povos autóctones, considerados atrasados e "selvagens". Neste âmbito, segundo Mbembe (2001), a assimilação fundou-se na possibilidade de uma experiência do mundo comum a todos os seres humanos, ou melhor, uma experiência de humanidade universal baseada na similaridade essencial entre os humanos. Todavia, durante o período colonial, cunhou-se a figura do "assimilado" indígena que, por meio do esforço individual e de seu progresso subalterno nas instituições educacionais criadas e ratificadas pelo Estado Colonial, aprenderia a língua e os costumes do colonizador para deixar de ser um "indígena" para se tornar um beneficiário da plena cidadania portuguesa. Segundo Mbembe (2001), para torna-se um assimilado, o africano deveria distanciar-se das suas tradições africanas e converter-se ao cristianismo aderindo assim às leis e às normas de conduta portuguesa.

A ideia da "assimilação" foi, portanto, desde o início do século XIX, um pressuposto basilar do sistema constitucional português e, de uma ou de outra forma, ela foi consubstancial ao quadro jurídico-legal em que os governos metropolitanos e coloniais fizeram assentar a política indígena. É neste contexto que Farré (2015) salienta que a República Portuguesa aprovou o Estatuto de Assimilado, em 1917, que era mais um instrumento de colonização, pois este novo decreto instaurado distinguia indígenas e não indígenas. Como sustenta Macagno (2014), através da Portaria no 317, de 9 de Janeiro de 1917, e aperfeiçoado posteriormente com o Decreto-lei no 39.666, de 1954, do Estatuto dos 
Indígenas, estabelecia que um indígena deveria reunir as seguintes condições para atingir o Estatuto de Assimilado:

- Saber ler, escrever e falar português de forma correcta;

- Ter meios suficientes para sustentar a família;

- Ter bom comportamento;

- Ter o nível de educação necessário e hábitos individuais e sociais aceitáveis pelas leis portuguesas;

- Fazer um requerimento à autoridade governamental para ser aprovado este estatuto.

Tendo em conta os pontos apresentados, para que um indivíduo transitasse da situação de indígena para a situação de assimilado, passava por vários processos de evolução considerados essenciais para tal. Atingindo esta fase, consideravam os colonos que o africano atingiu um estágio de evolução civilizatório aceitável pela mãe-pátria. Sendo assim, segundo Cabaço (2010), com a introdução desse decreto na colónia de Moçambique a população passou oficialmente a ser distinguida entre "cidadãos" (portugueses de origem e de cidadania adquirida) e sujeitos jurídicos que tendiam a se transformar em futuros cidadãos e cujo acesso à plena cidadania seria pautada por potencial gradualismo. Se a condição de indígena estava principalmente referida àquelas populações rurais ainda pouco afectadas pelos efeitos benéficos do contacto com a civilização portuguesa, os assimilados seriam os indivíduos que, por viverem nas cidades, estariam já dando mostras de uma forma de vida mais próxima à portuguesa: no uso da língua, na aceitação da vida cristã, na assunção do trabalho diário como forma de sustentar a família e na obediência às leis do governo, como as que se referem ao pagamento de impostos, ao serviço militar entre outros.

Para grande parte dos teóricos do colonialismo português, como Mbembe (2001), Macagno (2014) e outros, foram unânimes em afirmar que o assimilacionismo era claro e previsível, pois os indígenas estavam destinados a desaparecer. Isso tornar-se-ia possível a longo prazo, quando todos os africanos fossem integrados no processo de civilização e, de forma volutaria deixassem a sua condição de "selvagem/indígena". Segundo Malyn Newitt (1997), em 1945, haviam em Moçambique cerca de 1.845 assimilados, volvidos dez anos este número disparou para 4.554. Todavia, a administração colonial portuguesa não teve nada a ver com este considerável aumento. 
A responsabilidade deste aumento deveu-se quase que exclusivamente aos próprios moçambicanos interessados neste processo, pois a administração colonial nunca se mostrou preocupada com aumento desta categoria e alguns momentos criava entraves adoptando critérios e leis que retardassem o processo. Constata-se desta forma que os decretos-leis, ou seja, o sistema jurídico implementado pela administração colonial tinha como objectivo criar uma dualidade social baseada na segregação racial, passando a existir desta forma os "indígenas" e os "assimilados" e por cima destas duas classes sempre ficaram os "brancos/civilizados".

De salientar que, mesmo com a criação da categoria de assimilados, os negros nunca conseguiram alcançar o tão desejado, o de ocupar os mesmos espaços e cargos que os brancos na sociedade, pois a questão racial sempre pesou muito em todos os sentidos da sua vida. $\mathrm{E}$ os negros assimilados por muitos anos lutaram para ter de forma definitiva os mesmos direitos que os brancos. Nesta óptica, percebe-se que não bastava ser assimilado para gozar dos mesmos direitos que os brancos. Pode-se observar esta situação na seguinte ilustração:

No século XX, em Moçambique, uma elite de africanos assimilados de Lourenço Marques, na qual se destacava João Albasini e seus seguidores se insurgiu sob o seguinte slogan "somos todos portugueses". Este slogan veiculava uma rejeição as provas humilhantes pelas quais estes africanos tinham que atravessar para demonstrar sua condição de "civilizados" (MACAGNO, 2014, p. 34).

\subsection{A missão civilizadora como discurso de construção de identidade nacional portuguesa em Moçambique}

A missão civilizadora em Moçambique, desde os anos de 1800 , constituiu uma preocupação para o sistema colonial, principalmente depois de vários discursos discriminatórios proferidos por António Enes sobre a condição selvagem dos negros durante a ocupação efectiva deste território. A partir deste momento, várias leis e normas foram elaboradas no sentido de enquadrar o africano no sistema jurídico desenhado pelo colonialismo português. Nesta senda, pode-se dizer que a dinâmica da missão civilizadora portuguesa sofreu uma grande transformação com a aliança estabelecida entre o Estado Colonial e a Igreja Católica, pois em 7 de Maio de 1940, na celebração do 8o centenário de independência e a 3a década de instauração da República de Portugal, foram assinados a Concordata e o Acordo Missionário com vista a civilizar e integrar os povos africanos sobre os ditames da nação portuguesa. 
Na óptica de Medina (2016), a administração colonial primava pelo discurso da missão civilizadora para construir a identidade dos povos colonizados com base nos princípios da nação portuguesa. É assim que o sentido da nação a partir do olhar colonial se converte em um discurso que procurava justificar uma dupla visão do mundo, a reivindicação da posição dominante do colonizador (baseada numa missão ou finalidade superior que exalta sua condição civilizacional) e o determinismo cultural do dominado (baseado em uma postura evolucionista de atraso social frente aos grupos europeus). Por outro lado, a construção de uma identidade nacional estava envolvida também pela necessidade de exaltar e legitimar os ideais do regime colonial, deste modo qual os territórios coloniais passavam a fazer parte desse constructo.

No meu entender, durante todo o período colonial os portugueses apegaram-se ao discurso da missão civilizadora como forma de criar uma nação una e sem diferenças entre brancos e negros, procurando demostrar uma preocupação com a situação do povo de Moçambique. Mas, na prática, verificou-se que este discurso estava carregado de falácias, pois a ideia central era através da missão civilizadora segregar, subjugar e dominar os povos locais, criando assim a diferenciação social, política e cultural.

Segundo Macagno (2014), os princípios da nação portuguesa são implementados com a promulgação do Acto Colonial em 18 de Junho de 1930. Portanto, no seu artigo 2ำ o Acto Colonial estabelecia a essência orgânica da nação portuguesa: "desempenhar a função histórica de possuir e colonizar domínios ultramarinos e de civilizar as populações indígenas que nelas se compreendam, exercendo também a influência moral".

Na ideia de Medina (2016), a chamada missão civilizacional baseada sobretudo num discurso nacionalista pode ser vista como uma estratégia de acoplamento dos principais elementos identitários e sua função em respeito à pátria-mãe. Nesta sequência, o sucesso da missão consistia precisamente em estabelecer o destino português através de sua história e seus próprios mecanismos de forma a fazer uma reconstrução imperial, facto este que é vinculado de modo a manter uma diferenciação a partir da identidade local, mas que não conseguem se incluir dentro de uma perspectiva da nação. Nesta senda, os europeus seriam predominantemente vistos como gloriosos, poderosos, enérgicos, civilizadores. $E$, partindo das análises de Santos e Meneses (2006), verifica-se que, de forma a estabelecer um controle 
e uma administração eficaz até ao ponto mais remoto do território moçambicano, o governo colonial implementou a "missão civilizadora".

\section{A construção da alteridade colonial em Moçambique}

Na ideia de Boahen (2010), o colonialismo deixou marcas profundas em Moçambique assim como em muitos países africanos. Significou sobretudo uma política baseada no controle ou na autoridade sobre um território ocupado e administrado por um grupo de indivíduos, neste caso os portugueses, que, no século $\mathrm{XV}$, passou a ocupar e explorar Moçambique. Mas, esta ocupação só se efectivou depois da Conferência de Berlim em 1884/85, isto é, depois desta conferência, Moçambique se transforma oficialmente numa colónia de povoamento portuguesa. Para Fanon (1968), o colonialismo foi muito mais que um sistema definido apenas como exploração estrangeira dos recursos naturais de um território com recursos à mão-de-obra local, é, sobretudo, "a negação sistematizada do outro, uma decisão obstinada de recusar ao outro qualquer atributo de humanidade".

A alteridade colonial em Moçambique é produto de uma consciência histórica da missão civilizacional portuguesa, a qual é incluída dentro do discurso nacionalista formado como uma das partes fundamentais da identidade nacional. Na perspectiva de Said (1990), o colonizar por si só já era na prática um acto de identificação. Segundo Medina (2016), a alteridade se alude na capacidade das estruturas mentais e sua apreensão de uma realidade a partir de um processo de atribuição de identidade ou a partir da diferenciação. Portanto, a alteridade pressupõe o respeito pelos "outros", mas o que se assiste durante o período colonial português é totalmente o contrário, pois a política colonial obedecia a objectivos políticos, ideológicos e económicos muito bem definidos e claros que contribuíram para a negação do "outro" - os autóctones, neste caso os moçambicanos.

O colonialismo português, sempre procurou mostrar ao mundo que nutre uma excelente relação com os povos colonizados e que a sua acção civilizacional era vista como uma ajuda para que os mesmos saíssem do seu estágio atrasado. Todavia, esses discursos não constituíam a verdade, tanto que a administração colonial criou um sistema jurídico baseado na segregação. Conforme salienta Grigoletto (1998), o governo colonial sempre ignorou o passado da colónia, e tornou este passado ausente, como consequência desta ausência não 
se percebiam transformações, construções ou movimentos em direcção a um destino, o que daria a medida do estágio de civilização em que os habitantes do lugar se encontravam antes do início da colonização. Assim, o estágio anterior a colonização era percebido como ausência absoluta. E esta estratégia de redução ou ausência de um passado por parte das colónias foi fundamental para o discurso imperialista dos portugueses como justificativa para a imposição de uma nova ordem política na colónia sob o lema de se levar os benefícios da civilização moderna aos colonizados baseadas essencialmente na discrição entre "eu" (colonizador, sujeito civilizado) e o "outro" (colonizado) (KAVIRAJ, 1994). Este exemplo pode ser observado na seguinte frase de Meneses (2018): "é o ocidente que cria a alteridade africana como um espaço vazio de saberes, um recipiente oco, um corpo sem história e sem reflexão".

E para colocar esta política de alteridade em prática a administração colonial optou por fazer o deciframento do "outro", para isso recorreu às práticas antropológicas que foram fundamentais para o conhecimento da população nativa. Portanto, segundo Montero (2012), o colonialismo tomou como objecto de análise as etnografias elaboradas por missionários sobre as populações locais de Moçambique, ou seja, na descrição feita pelos missionários sem ter certeza da sua veracidade. Os estudos e as práticas missionárias contribuíram de forma contundente para alteridade das diferenças, reduzindo o "outro" ininteligível a um diferente. Como salienta Santana (2017), a realização de pesquisa de cunho etnográfico das populações locais foi o caminho que a administração colonial usou para conhecer e melhor "administrar" o "outro", nascendo assim um saber que justificava a dominação e a subordinação.

No entender de Montero (2012), a escrita missionária e seu modo de descrever os povos locais, partindo do pressuposto de que a forma como estes são descritos, está intimamente relacionada ao modo como a convivência entre os indígenas e missionários se desenrolou. Esta suposição, bem como a análise realizada a partir dela, traz importantes consequências para o modo como o colonialismo foi concebido em Moçambique.

Para Madeira (2007), a literatura de viagens apresentada pelos antropólogos portugueses oferece pontos de entrada privilegiados acerca do olhar e dos juízos de valor que são formulados sobre o "outro" acerca das acepções filosóficas e ideológicas da alteridade, no tempo e no espaço e, em particular, sobre as condições sociais de reprodução dessa relação. Segundo esta autora, muito do que era descrito nestas literaturas correspondia não ao que os viajantes viam, mas às expectativas do público ocidental, respeitando um estilo que ia ao 
encontro de uma realidade tal qual este imaginava. Neste âmbito, foi criada a "Missão Antropológica de Moçambique", em 1936, a primeira a ser instituída em resposta ao determinado pelo Decreto-Lei n.o 34 478, de 3 de Abril de 1935, e a única que funcionou regularmente até 1955; a obrigatoriedade, determinada em 1933 mas só regulamentada a partir de 1945 e em vigor até 1960, de os provimentos nas diferentes categorias da carreira administrativa em Moçambique se fazerem acompanhar de uma "monografia etnográfica" sobre uma das etnias da colónia; finalmente, a criação, em 1956-1957, da Missão de Estudos das Minorias Étnicas do Ultramar Português, especialmente dirigida a Moçambique e no seguimento da qual foi publicada, em quatro volumes, a monografia Os Macondes de Moçambique (PEREIRA, 2001).

Entretanto, a nossa pesquisa veio juntar-se à percepção dessa tão específica atenção antropológica sobre Moçambique: a fundação, por despacho de 31 de Julho de 1941 do Governador-Geral de Moçambique, General José Tristão de Bettencourt, de uma "Missão Etognósica de Moçambique" que, apoiada no estudo etnográfico das populações da colónia, procedesse à elaboração dos Códigos Penal e Civil dos Indígenas de Moçambique. Nota-se, deste modo, que a alteridade não é constituída ontologicamente, mas construída a partir do modo como os "outros" são descritos. Ou seja, tratava-se de um investimento que colocou em evidência a forma como a própria antropologia colonial foi constituída. Nesse sentido, vale destacar que o modo como a antropologia formulou suas questões relaciona-se intimamente ao tipo de inquietação dos missionários em seus esforços de compreensão e descrição das populações nativas com as quais trabalhavam. Assim, temas como parentesco ou família, religião e magia, cultura ou civilização constituíram-se como categorias formadoras de um quadro de referências que permitiu a uns e a outros "traduzir" os nativos em termos passíveis de serem compreendidos no mundo ocidental (MONTERO, 2012).

Os relatórios missionários contribuíram de forma considerável para a alteridade africana, surgindo assim o "indígena”, desprovido de conhecimento e pronto a ser preenchido pelo saber e cultura do Ocidente, foi o contraponto da exigência colonial de transportar a civilização e a sabedoria para povos vivendo supostamente nas trevas da ignorância. A segmentação básica da sociedade colonial entre "civilizados" e "selvagens/indígenas", conferiu consistência a todo o sistema colonial, transformando os autóctones em objectos naturais, sobre quem urgia agir, para os "introduzir" na história. 
Segundo Santana (2017), o desenvolvimento de interpretações acerca do "selvagem" teve início com o desenvolvimento da antropologia. No entanto, para Mudimbe (2013), várias escolas da antropologia deram início à construção de modelos e técnicas de descrição do "outro", baseadas em tendências explicativas em transformação do Ocidente. Esta perspectiva é também analisada por Santos e Meneses (2006); estes autores partem de uma análise feita em Portugal e Moçambique demonstrando que, no final do século XIX, a implantação da moderna colonização insistiu e apoiou-se numa hierarquização cultural, a partir da qual emerge, com grande nitidez, a ruptura entre o "europeu” e o "indígena", dando azo à emergência de vários estereótipos que doravante configurariam a representação dos colonizados.

Na verdade, o que se pressupunha era uma suposta tolerância dos usos e costumes dos colonizados como uma estratégia legal promulgada - era, além da adequação de um meio a um fim, ou além do trabalho como instrumento civilizador, o próprio processo de construção de uma representação. Isto é, o processo simbólico pelo qual o respeito e a tolerância significariam, ao mesmo tempo, a "produção" desses usos e costumes e a utilização de categorias para pensar a alteridade sob formas classificatórias que hierarquizassem e ordenassem seu próprio mundo: o "outro" como não civilizado, como carente de uma disciplina para o trabalho, subsumido sob a categoria homogeneizante e estigmatizante de indígena (a que se acrescentariam outros termos dados como sinónimos: rebeldes, cafres, perigosos, ociosos, criminosos, insensatos, indolentes, terroristas, educáveis, entre outros). Nesta vertente, com base nas pesquisas antropológicas, o governo colonial português começou a colonizar cientificamente Moçambique. E, com os vários discursos etnocentristas que surgiram após essas pesquisas, construiu-se a figura do "outro" baseada no atraso dos povos locais.

3. Alteridade e diferença: o discurso sobre a Negação do "outro" e a afirmação do "eu" em Moçambique colonial

A colonização, enquanto sistema de negação da dignidade humana para muitos povos do mundo, simbolizava um imenso espaço-tempo de sofrimento, opressão e resistência (MENESES, 2018, p. 118).

Olhando a citação em epígrafe, a implantação do sistema colonial desde o seu início já pressupunha a ideia da diferença como forma de negar outras culturas e valorizar a cultura ocidental. Com base nos vários estudos etnográficos, como vimos no ponto acima, chegou-se 
a conclusão que era possível hierarquizar as culturas e seus povos, nesse caso o povo moçambicano. Portanto, ao adoptarem esta posição contrariavam a teoria relativista de que todas culturas têm características próprias e não é possível quantificar de forma a escalonar. No entanto, as diferenças entre elas devem ser respeitadas e não ignoradas, devem ser enfatizadas não pelo lado negativo, de fragmentação, segmentação e alienação, mas como uma mais-valia, pelo poder que tem enquanto ferramentas de afirmação identitária.

Na perspectiva de Eva Dinis (2009), as diferenças culturais e individuais é que demarcam o espaço entre o "eu" e o "outro", portanto, é necessário lembrar que estas diferenças funcionam como um fenómeno da autodeterminação das minorias, deste modo, não devem ser alvo de classificações vigente em contextos coloniais, uma vez que estas diferenças que se enfatizam nesses contextos podem ser muitas vezes processadas pelo "eu" que pretende demarcar a identidade do "outro" através de uma perspectiva negativa. Todavia, a diferença é um processo que resulta de um exercício de alteridade. Ou seja, a alteridade do "eu" só é definida na presença do "outro", e vice-versa, apesar de a representação do "outro" pelo "eu" não se bastar a si próprio na criação das identidades, uma vez que esta seria insuficiente e deficitária, mostrando apenas uma perspectiva invariavelmente marcada pela incompreensão ou, pelo menos, por uma falta de compreensão total. A autora salienta ainda que a diferença é um dos elementos indispensáveis na afirmação do "eu" face à alteridade. O local da diferença é assim o ponto em que a discussão das diferenças está aberta para um diálogo intercultural. Porém, se a admissão das diferenças pode levar à auto determinação, é necessário ter também em atenção que esta diferenciação construída sobre o binómio "eu" e "outro" pode ser desconstruída de modo a inferiorizar uma das partes visadas, podendo delimitar de modo restrito o que corresponde à identidade do "eu" (e do nós), e o que é o "outro", que pode ficar prescrito aos estatutos de representação classificatória. Neste contexto, a desvalorização e inferiorização do povo moçambicano.

Dispostos a montar uma máquina administrativa coerente com os seus objectivos, o governo colonial também vai se valer da teoria evolucionista criada por Charles Darwin de que as espécies não evoluem da mesma maneira apregoando, assim, a existência de uma raça superior (branca) e a raça inferior (negra). Deste modo, criou-se a ideia do "eu" (colonizador) e "outros" (colonizado). É a partir destas formulações que Grigolleto (1998) traz à ribalta a retórica do evolucionismo como uma associação do discurso colonial para o rebaixamento do 
colonizado, visto como sujeito sujo e abjecto e, por conseguinte, incivilizado e inferior, e a negação de uma história para a colónia, história anterior à colonização. Nessa visão, o passado de Moçambique foi completamente ignorado, entendido desta forma como ausência, o que significa interpretar tanto a terra quanto o seu habitante como vivenciando um eterno presente como consequência da ausência de história e do eterno presente como consequência não se percebem transformações, construções ou movimento em direcção a um destino, o que daria a medida do estágio de civilização em que os habitantes do lugar se encontravam antes do início da colonização. Assim, a história do povo moçambicano anterior à chegada dos colonos foi completamente ignorada e apagada.

Na perspectiva de Meneses (2010), o evolucionismo serviu como um paradigma da narrativa colonial, protegendo as ideias sobre as diferenças raciais, o destino e a hierarquia conjugados possibilitaram ainda a constituição de uma moldura jurídico-legal que justificava uma intervenção normativa colonial moderna. As diferentes formas de que este encontro colonial se revestiu em Moçambique (assimilacionismo, administração indirecta, segregação racial, entre outros) encontraram a sua fundamentação na obrigação moral de Portugal actuar no sentido de fazer progredir o indígena para estágios civilizacionais mais avançados.

Kaviraj (1994) argumenta que a estratégia de redução do "outro" a uma essência imutável e não-histórica foi fundamental para o discurso imperialista como justificativa para a imposição de uma nova ordem política na colónia sob a forma de se levar os benefícios da civilização moderna. Afirma o autor que houve a propagação de duas formas de essencialismo pelo discurso colonial português, que podem ser descritas em:

- A primeira era a dicotomia essencialista entre o "eu" (colonizador, sujeito civilizado) e o "outro". O "eu" era retratado como um ser histórico, determinado e capaz de reformas radicais, enquanto o "outro" era visto como vazio, abstracto e depositário de características negativas, não no sentido de péssimos, mais sim de ausência como consequência;

- A segunda forma de essencialismo apresentava o "eu" como possuidor de uma representação histórica muito mais densa que o "outro". Havia ou não a negação da história ao outro pura e simplesmente ou a construção de características estáveis e quase transcendentais que a história podia alterar. 
Durante todo o processo de implementação do sistema colonial e dominação, o discurso imperialista no século XIX se baseou na ideia de reconstruir a história moçambicana com base num modelo europeu, isto é, dar uma história aos moçambicanos procurando assim decifrar eventos incompreensíveis sob a óptica da narrativa ocidental. Essa posição portuguesa reflectia-se nos discursos políticos ao longo do século em Moçambique. A negação como figura que caracteriza a colónia e o colonizado corresponde a afirmação como figura atribuída ao colonizador.

Segundo Cabaço (2010), as exigências da ocupação efectiva dos territórios induziam a que, sob mesma palavra, se incorporassem influências pragmáticas do capitalismo industrial anglo-saxónico e lhe fosse atribuído um sentido mais "tendencial", subordinado ao imperativo da exploração da mão-de-obra indígena: os colonizados deixavam de ser "iguais" para serem "tendencialmente" passíveis de se tornarem iguais. Para o capitalismo era preciso que os homens fossem "diferentes" para se justificar a diferente atribuição de seus direitos. Para este autor, a noção da alteridade é, com ela, o preconceito racial se radicalizarão com o novo contendo da palavra assimilação.

A colonização se baseou na negação da condição humana do outro, as comunidades autóctones foram (des)classificadas, passando a ser designadas em indígenas. Esse processo de desclassificação do outro simultaneamente elevou o branco, europeu, a condição de um verdadeiro homem, civilizado e detentor de sabedoria racional. E, através deste discurso, os portugueses conseguiram alterar a essência do povo moçambicano, sobretudo a educação tradicional dos indígenas, incutindo uma educação baseada na discriminação racial. Esta alteração contribuiu para que, dentro do território moçambicano, surgissem grandes diferenças a nível educacional, racial e cultural.

Neste entender, pode-se perceber que é a partir das questões culturais que se inscreve a identidade com base na diferença, na relação do "eu" com o "outro", ou seja, na alteridade. O papel da alteridade se reveste de maior importância, uma vez que é através de constantes reenquadramentos identitários que se fundamenta a construção do "eu" e do "outro", a alteridade é, portanto, indissociável da noção da diferença e identidade (DINIS, 2009). Para Said (1990), a estrutura básica para montagem do aparato da alteridade e diferença foi montada com base no "nós", os europeus, versus "eles", os povos do ultramar. 
Na óptica do autor, o "nós" sentia-se responsável pela emissão de um determinado saber sobre "eles".

\section{Considerações finais}

Durante o estudo constatou-se que a missão civilizadora implementada por Portugal escondia as verdadeiras motivações que eram de subjugar e dominar os povos considerados "primitivos". Pois, na óptica dos portugueses, o povo moçambicano não possuía instituições religiosas, normas e regras de convivência, ou seja, era um povo incapaz de se autogovernar. Nesta senda, Portugal assegurou em Moçambique o direito histórico de fomentar o progresso das culturas "primitivas" em função do estágio de desenvolvimento económico, cultural e político de que gozava. Estas conviç̧ões e preconceitos encontraram consagração numa série de quadros legais, procurando justificar a política colonial de Portugal, criando categorias legais subalternas, como foi o caso dos "indígenas". E, a partir desta categoria, surgiu a do assimilado, que permitia ao negro uma mobilidade social de indígena para cidadão português, com base num conjunto de preceitos impostos pela administração colonial. Com base neste cenário, foi criada a ideia de alteridade e diferença colonial que reconhecia esses povos como os "outros" coloniais, como seres a-históricos, ou seja, seres sem história que precisavam ser civilizados e instruídos pelo "eu" (colonizador) para construir uma nova história.

\section{REFERÊNCIAS BIBLIOGRÁFICAS}

CABAÇO, José Luís de Oliveira. Moçambique: identidades, colonialismo e libertação. São Paulo: Anpocs, 2010.

DINIS, Eva Maria Afonso Moreira da Cruz. Dois olhares sobre alteridade: o outro em a correspondência de Fradique Mendes, de Eça de Queirós e Nação crioula, de José Eduardo Agualusa. Dissertação de Mestrado em Língua e Cultura Portuguesa apresentada a Universidade de Lisboa, 2009.

FANON, Frantz. Os condenados da Terra. Brasil: Editora Civilização Brasileira, 1968.

FARRÉ, Albert. (2015). Assimilados, Régulos, Homens Novos, Moçambicanos genuínos: a persistência da exclusão em Moçambique. Anuário Antropológico II. 2015. Disponível em: http://journals.openedition.org/aa/1443. Doi:10.4000/aa.1443.pp.199-229.

FILHO, Wilson Trajano; DIAS, Juliana Braz. O colonialismo em África e seus legados: classificação e poder no ordenamento da vida social. Anuário antropológico, 2015. Disponível em: https://doi.org/10.4000/aa.1371.

GRIGOLETTO, Marisa. A resistência das palavras: um estudo de discurso político britânico sobre India (1942-1947). Tese apresentada ao curso de Linguística da Unicamp, Brasil, 1998. 
KIVIRAJ, Sudipta. On the construction of colonial power: structure, discourse, hegemony. In: ENGELS, D \& MARKS, S (eds). Contesting colonial hegemony: state and society in Africa and India. London: British Academic Press, 1994.

MACAGNO, Lorenzo. Assimilacionismo. In: SANSONE, Lívio; FURTADO, Cláudio Alves (org.) Dicionário crítico das ciências sociais dos países de fala oficial portuguesa. Salvador: EDUFBA, 2014.

MADEIRA, Ana Isabel. Ler escrever e orar: uma análise histórica e comparada dos discursos sobre a educação, ensino e a escola em Moçambique, 1850 -1950. Tese de Doutoramento em Ciências da Educação apresentada a Universidade de Lisboa, 2007.

MBEMBE, Achille. As formas africanas de Auto-inscrição. Estudos Afro-asiáticos [online]. 2001, v. 23, n. 1, p.171-209. Disponível em: https://doi.org/10.1590/\$0101-546*2001000100007.

MEDINA, Guillermo. Representando a ideologia: a ideia da alteridade colonial. Revista da I Exposição Colonial Portuguesa. Brasil, 11 Agosto de 2016.

MENESES, Maria Paula. O "indígena" africano e o colono "europeu": a construção da diferença por processos legais. e-cadernos CES [Online], 07, 2010, Online since 01 March 2010, connection on 31 July 2019. Disponível em: http://journals.openedition.org/eces/403 ; DOI : 10.4000/eces.403.

MENESES, Maria Paula. Colonialismo como Violência: a "missão civilizadora" de Portugal em Moçambique. Revista Crítica. Coimbra, CES, 2018.

MONTERO, Paula. Selvagens, civilizados, autênticos: a produção das Diferenças nas etnografias Salesianas. Brasil: EDUSP, 2012.

MUDIMBE, Valentin Yves. A invenção de África: gnose, filosofia e a ordem do conhecimento. Tradução Ana Medeiros. Mangualdes: Pedago, 2013.

NEWITT, Malyn. História de Moçambique. Lisboa: Publicações Europa-América, 1997.

PEREIRA, Rui Mateus. A missão etognósica de Moçambique: a codificação dos usos e costumes indígenas no direito colonial português. Cadernos de estudos Africanos. Brasil, Centro de estudos internacionais, 2001.

SAID, Edward W. Orientalismo: o oriente como invenção do ocidente. Tradução Tomas Rosa Bueno. São Paulo: Companhia das Letras, 1990.

SANTANA, Cristiane Soares de. Saberes coloniais: Missão etognósica de Moçambique e a proposta de "Código Penal" de José Gonçalves Cotta. Tese de Doutoramento em História apresentada a Faculdade de Filosofia e Ciências Humanas da Universidade da Bahia, 2017.

SANTOS, Boaventura de Sousa; MENESES, Maria Paula. Identidades, colonizadores e colonizados: Portugal e Moçambique. Relatório final do projecto POCTI/41280/SOC/2001. Coimbra: CES, 2006. 